\title{
Middle-aged women negotiating the ageing process through participation in outdoor adventure activities
}

Yvette Wharton

This is the accepted manuscript of an article published in Ageing and Society, 2018.

The published article is available from:

https://doi.org/10.1017/S0144686X18001356 


\title{
Middle Aged Women Negotiating the Ageing Process through Participation in Outdoor Adventure Activities
}

\author{
C. Yvette Wharton ${ }^{1}$ \\ ${ }^{1}$ Abertay University, \\ y.wharton@abertay.ac.uk \\ Division of Sport \& Exercise Sciences, Bell Street, Dundee. DD1 1HG UK.
}

\begin{abstract}
This study sought to examine the motivations middle aged women give for belonging to an outdoor adventure group. As part of this, how the women were negotiating the ageing process was also examined. Fourteen women aged 36-64 (average age 51.4 years) were individually interviewed with the purpose of exploring their perceptions, values, motivations, and the beliefs they attach to their participation. Findings highlight the women's belief that participation delays the ageing process, gives them confidence in their lives, and offers social support from other group members. In addition pride, satisfaction, and pleasure were expressed in the belief that they challenged the cultural norms and expectations of older women. Whilst delaying the ageing process they also highlighted that they thought about a time in the future when they would not be able to continue to participate. The study emphasises that more adventurous activities are becoming more normalised and can be undertaken by women in middle age. This may also suggest that more needs to be done to promote diverse activities such as outdoor adventurous activities to women.
\end{abstract}

Key Words: Middle aged, women, adventure, physical activity, outdoor, ageing.

\section{Introduction}

Women's physical activity participation levels are lower than men's, with participation rates declining with age (Scottish Government 2016; Althoff et al. 2017; Sport England 2017). It is suggested that during middle age women's participation in regular physical activity declines by up to half, at the same time as declines in basal metabolic rate and loss of lean body mass occur, which have the potential to result in increased risk of weight gain and related health co-morbidities (McArthur et al. 2014). There are many reasons why women do not participate in regular exercise. The likelihood of participating in exercise is influenced by many factors including age, sex and life stage (Jones, Millward and Buraimo 2011). There are strong associations between life events that both increase and decrease participation, with these varying across age groups and across the lifespan (Campbell et al. 2001; Brown, Hesch and Miller 2009). Some of these, as noted by Little 
(2002) are structural factors that include family, financial resources and life course stages. Middle aged women tend to attribute the demands of life, lack of time, outdoor exercise and not having someone to exercise with as contributing to non-participation (Im et al. 2008). As people age, individuals tend to cite health more frequently as a reason for not participating in exercise (Scottish Government 2015). Analysis of reasons for participating in exercise varies between men and women with men more likely to have higher scores for enjoyment, improving performance and taking part in competition, whilst women's motivations are more likely to be losing weight and taking children to activities (Scottish Government 2015).

Participation in swimming and health and fitness activities such as aerobics classes tend to account for most activities undertaken by women, whilst men tend to engage in a wider range of activities (Jones, Millward and Buraimo 2011; Scottish Government 2016). One exception to this is the popularity of hill walking which both men and women enjoy and, unlike other activities this has not seen a decline in recent years (Scottish Government 2015). However, in other outdoor adventure activities such as backpacking, climbing, canoeing or mountaineering, women's participation rates are considerably lower than those of men (Nolan and Priest 1994; Jones, Milward and Buraimo 2011). Adventure activities have tended to be the reserve of men, reflecting the perception of an association between these activities and what are seen as masculine qualities, such as strength and risk taking (Little 2002; Anderson 1999; Ford and Brown 2006; Thorpe 2011). There is evidence to suggest that women may avoid some adventure activities because of perceptions of risk (Boyes, 2013). As a consequence of identifying outdoor adventure activity as an area of masculinity, women are denied access resulting in an under representation (Humberstone 2000; Coalter and Dowers 2006). It has been suggested that the gendered and sexualised nature of many activities and leisure contexts can explain why women are often alienated from taking part in certain activities (James 2000; Scraton and Watson 1998). The choice of sporting activities made by individuals may therefore reflect the culturally sanctioned values of these activities within society (Eccles 1994) and 
replicate and magnify gendered issues (Roth and Basow 2004). This may explain lower levels of participation in physical activity, especially outdoor adventure pursuits.

Yet many women from diverse backgrounds do participate in adventure activities, but in far fewer numbers than men (Little 2002). Research suggests that although outdoor adventure leisure is both physically and intellectually challenging there is potential for women to receive many positive benefits from engaging in these activities (Pohl, Borrie and Patterson 2000; Little 2002). Laurendeau and Sharara (2008) posit that there is no reason to believe that women are unable to participate or to access adventure on their own terms. If adventure activities are appropriately led by effective leaders, women have been found to be able to balance negative perceptions and risk associated with adventure (Boyes 2013). By participating in adventure activities women are able to experience numerous benefits, including self-discovery, reduced self-doubt, physical competence, selfawareness and social interaction (Henderson 1992; Little 2002). There is an increasingly held belief that older sports women have the potential to challenge and disprove culturally held beliefs about the physical abilities of the ageing female body (Hargreaves 1994). Breivik (2010) suggests that women adventure participants act as 'trendsetters'. Despite this, women continue to experience more barriers associated with participation, with this being particularly evident with outdoor exercise (Kilgour and Parker 2013; Anderson and Noble 2001). Little (2002) suggests that due to the male dominated history of adventure recreation that research in outdoor adventure activity has been predominantly focussed on men. In addition the nature of the type of physical activities undertaken by women has resulted in research being focussed on indoor and traditional sport and exercise contexts normally associated with women's participation (Kilgour and Parker 2013).

\section{Purpose of study}

The purpose of this study was to explore the motivations and experiences of a group of middle aged women belonging to an outdoor adventure leisure group. Although there are a number of 
definitions of adventure activities for the purpose of this study the definition of Holyfield, Jonas and Zakicek's (2005) is used which focusses on recreational adventure activities as experiential. These are voluntary, uncertain and intense and are experienced in an emotional context. In addition participation has the capacity to enable individuals to "achieve distance from all too familiar worlds" (p185). The main reason for the study is to provide an understanding of the underpinning reasons for the women being part of the group. Within this aim the study also examined how women participating in outdoor adventure activities reflected on ageing and how they experienced the activities in light of ageing.

\section{Methods}

As women belonging to an outdoor activity group were the central focus of the study, purposeful sampling was used, with participants being drawn from a women's outdoor adventure group, based in the Dundee and North Fife area, Scotland. Following approval from university ethics committee all members of the group (N20) (36yrs - 64yrs) were invited to participate. An email was sent to each member outlining the purpose of study, explaining how the study would be organised and inviting them to participate. From this 14 subsequently participated in interviews.

Interviewees group demographics

Information about the participants, age, marital status, employment status, level of education and number of children is given in table 1.

Table 1

\section{Group description}

The group was originally formed in 2007 following a 'women only' adventure taster course run for eight women by a female instructor under the auspices of a local authority outdoor centre. This 
course allowed women to engage in six different adventure activities over a six week period. These activities included mountain biking, canoeing, coasteering, land yachting, climbing and gorge walking. For most of the women this was the first experience of some of the activities. Their enjoyment of the activities was such that they asked the instructor to organise further activities for them. The original course format was repeated twice with the same outcome, resulting in women from these later courses joining those from the first. In addition to those who had participated in courses, friends of the women were invited to come along and over time a cohesive group formed that identified itself as a women's adventure group. For the first few years activities were organised by the original instructor and included day activities such as hill walking, canoeing, coasteering, winter skills and also going away for weekend activities.

When the female instructor left the outdoor centre the women were faced with stopping the activities, continuing with a male instructor or organising activities on their own. They chose to continue on their own, only using instructors for specialist activities such as coasteering. A number of the women periodically take on the role of organiser of activities; in addition to enhance their skills some have undertaken courses in navigation and kayaking. Once a month they try to do one activity; they go away for occasional weekend activities and each year they organise an activity lasting up to a week long, which has included long distance walks and a canoeing expedition. In addition to the actual adventure activities there are also social gatherings, including periodic coffee meetings to discuss and plan future activities and also an end of year dinner where they share photos and memories of what they have done during the previous year. They also celebrate notable birthdays such as 50 and 60 years with weekends away based around outdoor adventure.

The current research sought to examine the experience of outdoor adventure through the experiences of a women's adventure group. A phenomenological approach was utilised to develop analysis and describe the experience of adventure in the women's lives (Creswell 2013). Through 
interviews, first hand descriptions of the phenomenon of adventure have been gathered, with this approach allowing for the essence of this experience in the women's lives to be captured (EddlesHirsch 2015). The focus was on determining the meaning of adventure to the participants in their everyday lives and how this impacted on their identity. The number of interviews carried out allowed for depth of data and richness to be obtained. Topics and prompts allowed for individual personal experiences to be gathered enabling participants to 'tell their story.' Through the interviews and subsequent analysis of these it was possible to provide an in depth description of how adventure was a lived experience in the women's lives (Finlay 2008).

\section{Procedures}

A semi structured interview method was selected to provide focus but also allowed individuals to express freely their own perspectives and experiences. Individual face to face interviews lasting approximately 40-60 minutes were undertaken to gain individual perspectives. The interviews took place in a location and time convenient to each participant; for example locations included an office of the university and individual's homes. An agenda of topics was used to ensure that relevant issues related to the research area were systematically covered, also allowing flexibility to pursue details pertinent to individual participants (Arthur and Nazroo 2003). All interviews were voice recorded using a digital Dictaphone, and subsequently transcribed verbatim.

Initial questions focused on demographics such as age, employment and education. To develop focus and encourage discussion a number of topics were explored. These focussed on exploring the women's motives for being part of the group; their experiences of participating in the activities and how ageing impacted on their experience. An open questioning technique was employed to allow the individual's answers to direct the flow of the interview and reflect their own individual experiences. A thematic analysis approach was utilised to establish themes, patterns and allow for interpretation of data (Braun and Clarke 2006; Boyatzis 1998). This was achieved through familiarisation with data 
through transcriptions (Riessman 1993) and re-reading transcripts repeatedly and taking notes. Initial reading was directed at becoming empathetically immersed to allow for reflection on the phenomenon. From this, data was organised into meaningful groups (Tuckett 2005) resulting in the generation of structure, coherence and clustering which led to the identification of themes. After initial themes were identified and to ensure the findings were shaped by the responses of the participants, member checking was undertaken. This was achieved by presenting findings to a sub group of the women with the purpose of allowing the women to give feedback and ensure authentic interpretation (Creswell, 2013; Thomas, 2017). This allowed for interpretation of data to be verified by allowing participants to comment on researcher analysis (Noble and Smith 2015). Following this the themes were further reviewed to discern additional meanings and their inter-relationships (Von Eckartsberg 1998). Themes were subsequently renamed to refine concepts that accurately represented participant beliefs, values and meanings they attached to adventure activities (AttrideStirling 2001).

The researcher is actively involved in sport and exercise through participation and as an academic. Within the current research her role is that of a participant researcher, taking part in the first taster course and participating in a number of activities since. As such, it is recognised that she holds similar perspectives to the participants. This allowed the interviewer an insider's perspective that provided an opportunity to probe and develop questions. The researcher is however aware that this positioning could bias the interpretation of data.

\section{Findings and discussion}

\section{Identified themes}

Following analysis a number of themes around belonging, confidence, and ageing were identified. The key themes that are explored in this paper are given in Table 1. 
Table 2

\section{Group belonging}

The group offers a supportive situation and opportunity to engage with the environment. This is highlighted by the emphasis the women place on group identity that has both social and adventure components.

\section{Social support}

Every comment made about the group was positive, with all participants highlighting how important the group had become to them. The group was a point of reference to organise activities around and to create challenges, and to provide alternatives to other commitments in their lives. One woman compared it to "a natural family, a family that you choose." This is an interesting point and one that has been observed previously. Fredrickson and Anderson (1999) found in their study of women participating in wilderness expeditions that the women reported the bonds and support they experienced were at times greater than that received from family and significant others. This also reflects other research that seems to suggest that unlike men who focus on the activity women are more focused on relationships that are formed during the activities (Kiewa 2001). The women in this study acknowledged that the group was formed by chance and without it they would probably never have met nor had the opportunity to experience the activities and adventures. The group has become a potent force in their lives, providing the opportunities to challenge themselves, but also a powerful social resource offering support and companionship. Without exception all remarked on the qualities of the women in the group, using words such as proud, remarkable, fantastic, and inspirational. 
"I have never looked back. I have met so many fantastic people, I've had so many fantastic experiences and it has just been completely life changing."

"I feel privileged to be a part of this group; it's a real privilege to me. And something that when I think twenty years ago how would I see my life going I wouldn't necessarily have thought this would be part of it, so I think that's a really important factor and it's good."

There were no obvious divisions or tensions, with many remarking on how consistent, cooperative and supportive all the other women were. Some used examples of difficulties they had experienced in their personal lives and how the women had been a positive supporting presence during these times. The opportunity to socialise and make new friends has been found to be a major benefit from engaging in activity, giving the opportunity to communicate with others through shared ideas and experiences (Nolan 2010; Ferrand 2008). This emphasis on these relational bonds has been found to be clearly prevalent in women (Henderson 1996). It has even been suggested that the relationships that are formed through undertaking adventure activities together may be more important than the actual physical challenges that are experienced (Fredrickson and Anderson 1999; Boniface 2006). Such is the synergy that has developed within the women's group that one woman commented on how the interconnectedness between the group enabled them to achieve and accomplish tasks and overcome obstacles as if it was choreographed, likening it to a dance.

"Everything is like a dance, everyone knows their move, that's exactly it, we know our strengths we know how we complement each other you just do and let the dance happen, then you get the canoes over the fence and across the road." 
The expressed bonds and support may reflect aspects of Loeffler's (1997) research that proposed that women's willingness to take part in risks associated with adventure is enhanced when the environment is nurturing and supportive.

\section{Different from social norms}

They liked the idea that they were different from other women of their age. They were particularly proud that they belonged to the group and were doing things that most women of their age avoid. Alongside this they also delighted in the belief that they required a certain degree of 'madness' to do the activities, and this gave them courage to meet the challenges of being in the outdoors, but also something they believed distinguished them from others.

"My friends that I work with think I'm nuts, that I'm absolutely nuts. And every Friday it's "what adventures are you doing this weekend, what part of the world are you in this weekend?" They think I'm nuts."

"My family and friends think I'm actually a bit nuts, (laughs) actually I am a bit nuts."

"They sort of ask; things like for instance about the Great Glen Canoe, "well why did you camp? Could you not have stayed in a hotel?" And I think well we could have done (laughs) but where's the challenge in that?"

"My mother doesn't get it, she always asks why do I want to do that, have you nothing better to do with your time? I'm just glad I do."

For women it has been suggested that there is a socially orientated need to participate in exercise as part of a group and for the group to be seen as being defined by its distinctiveness (Edmunds, Duda 
and Ntoumanis 2010). It was clearly evident from the women that they regarded themselves as being different to what were the expected social norms for their age group. It has been found that group distinctiveness can be a predictor of more self-determined forms of motivation (Edmunds, Duda and Ntoumanis 2010). Their thinking and beliefs about the activities they participate in gave them confidence and a certain pride in standing outside the traditional norms associated with adventure activities and their age. Participating with the group and doing things that are not regarded as the norm certainly motivated them to want to participate and to push themselves. Although recognising themselves as being different, they are confident and comfortable in their position as adventure enthusiasts and are not restricted by regarding adventure activities as masculine or being male dominated, which Humberstone (2000) has put forward as reasons for nonparticipation. It could be suggested that the women have an openness to experience that results in greater flexibility and thus have an attraction to unconventional ideas (McCrae 1987), enabling them to step away from conformist concepts and perceptions of what women should be or do. An openness to experience has been related to self-perceptions of ageing that influences whether an individual experiences themselves as young or old (Canada et al. 2013). As such it boosts their confidence and belief in their own abilities.

\section{Self-perception and identity}

All participants acknowledged the value of the activities and spoke about what it was they took from both the actions of doing the activities but also accomplishing them. Everyone highlighted how much they enjoyed the activity and acknowledged how uplifting these experiences were. They commented on the weather, the risks associated with activities and being outdoors and how much these contributed and added to the sense of accomplishment. 
"Encouraging everyone to finish the activity, at the end when everyone is windswept and maybe soaking wet or really hot, it's a great sense of achievement when we all as a group finish."

Outdoor activity and weather conditions have been found to be common barriers to middle-aged women exercising (Im et al. 2008). Yet for the women adverse weather conditions were to be battled, overcome and even enjoyed; for some it was an almost liberating experience. They were aware of the risks associated with being in the Scottish mountains but were able to manage this.

In contrast to Little's (2002) study, all of the participants were able to incorporate the positive outcomes into their sense of self. Adventure recreation had become part of their identity. It is interesting to note that the focus of all of the women was very much on the experience; what they took from the activity rather than the activity itself. The experiencing of the elements, camaraderie, being together and sharing were as important as or even more important than reaching the top of the mountain. The diverse nature of their adventure experiences challenged them both physically and mentally resulting in a redefining of how they view themselves. There was a strong narrative running through the interviews that repeatedly emphasised the changes the women observed in themselves.

"........more confident more independent."

“....about lifting your mood."

"I love it I suppose really, it's just, it's been an unexpected part of my life that I wish I'd had when the kids were younger."

"It's an inspiration." 
Previous research found that participating in activities in the outdoors elicits positive changes that enhance self-concept and self-perception (Fredrickson and Anderson 1999). In addition Kaplan and Kaplan (1989) drew attention to how outdoor experiences had the potential to produce feelings of competence and self-confidence. Although it is suggested that it is only through repeated experience of the outdoors that changes in the self will be experienced (Brookes 2003). The women in the group have achieved this repeated experience by participating in regular monthly outings and weekends away. Their confidence can be observed not only in their desire to participate in activities with the group but it has also expanded to them being more independent. Many of those interviewed now engage in activities on their own or have extended their friendship circle and participate with others in outdoor adventure separate from the group. Also their decision to manage the group activities on their own when the original instructor left is also testament to their increased confidence.

\section{Ageing}

Decline and regret

In addition to the many positive aspects of participating the women also reflected on the impact an ageing body may have. This was mentioned in how this already influenced participation but also the possible future consequences Previous research has put forward that there can be an over medicalization of ageing and as a consequence the focus can be directed to the decline of the body (Pfister 2012). Decline was part of the women's reflections in relation to specific questions about ageing. There was acknowledgment of future limitations that may accompany ageing, but alongside this was also the notion of trying to limit this. Although decline and deterioration were mentioned, these were not a dominant part of their narrative. They commented on two aspects in relation to not being able to do the activities; these were the physical limitations that often accompany ageing and their response to possibly having to give up participating. 
"In terms of the physical aspects of ageing, I absolutely some days ache to bits."

"I would hate to think that I couldn't do the activities."

"I dread that time, I dread that time."

"I would be absolutely gutted, I think my self-worth would be pretty ****, I can't imagine life without it."

There was also a strong focus on maintaining fitness and carrying on participating in activities for as long as possible. Aspects of not trying to predict the future were also mentioned and seizing the opportunities that life presents.

"No, I don't think that far ahead, it's like this is what we are doing now, and because the fact that we have been doing it for so long, we can continue because we feel we can but still pushing yourself a little."

"It made me realise that live for every day, keep fit, do things that you want to do".

"I think that is the thing about the outdoors is it's not age limiting, because you can be in your 50s, 60 or 70 s and still do things outdoors."

There was recognition that there are already aches and pains and there may come a time when as a consequence of physical limitations they may have to give up or change the type of activities they do. Yet alongside this there was preparation to avoid or limit this. There was a determination that they will keep going for as long as possible. Although there was recognition of problems, actually 
exercising may in itself delay the point at which they have to give up or curtail certain activities. Current evidence suggests that the benefits of exercising at their age acts has a protective factor against sarcopenia in old age, maintaining muscle strength, motor function and as a consequence physical performance (Akune et al. 2014; Kamijo and Murakami 2009). Pfister (2012) raised the notion that remaining young, slimness or beauty, which can be seen as devaluing ageing are reasons associated with denying the ageing process; these however were not part of the narrative of the women in this study. Rather keeping fit and active were things to be done to allow them to continue to be engaged in adventure.

It was also recognised that it is not possible to predict the future and as such it was important to extract enjoyment from the now.

"Obviously it's going to happen as we get older, that capabilities might not be the same but I just think with the way we are - positive, we do try to keep fit and healthy, I just hope that we have many years still together."

This emphasis on living in the now reflected the belief that the future was unpredictable and as such should not be second guessed. As seen, with regards to their health, participants in the present study were pro-active in trying to maintain health. The desire to do the activities encouraged them to want to continue. The combination of the dynamics of belonging to the group and the nature of the activities they undertake positively impacted on their perception of ageing and their aspiration to remain active. There was acknowledgement of some limitations associated with ageing but their major concern was on putting things in place that enabled continued participation. This would be achieved by remaining positive and being prepared to adapt activities to accommodate limitations. By making adaptations they believed adventure participation would be prolonged. 


\section{Role models}

Although the average age of the group was 51 years the age span of the group was 36-64 years. Younger members of the group remarked that the older women were to be esteemed and that they acted as an incentive to continue. The older women's participation and ability was an example to be admired as an illustration of good ageing, of what could be achieved and should be emulated. The younger women's views of older members laid down a foundation of beliefs about future possibilities and expectations.

".......it's inspirational to see the other women who are there and possibly older but extremely fit. To see everybody out there is phenomenal so yes that, I like to see that because it is an incentive to keep fit so that I can keep doing the same, but it lets me see higher level of fitness is still achievable."

"The older ones are inspiring; none of us can say we can't do that because we are too old."

".......they just seem as young at heart as the rest of us, so I think that if they can do it so can I."

The pervading views of ageing can often be negative resulting in attitudes and beliefs that are dominated by a negative discourse that emphasises ill health, reduced functioning and loneliness (Wurm et al. 2013; Horton, Baker \& Deakin, 2007). Ageing stereotypes have been shown to have detrimental effects on physical and mental performance and health in older adults (Freeman, et al 2016; Meisnar, 2012). Repeated exposure to negative stereotypes can serve as catalysts that result in individuals internalising this pessimistic perception (Levy, Chung and Canavan, 2011). Selfperceptions of ageing play a significant a role in the way individuals age (Wolff et al. 2015). These perceptions are an amalgam of life experiences, expectations and societal attitudes that subsequently impact on behaviour (Levy 2009). Understanding of the role others may play in 
shaping perceptions of ageing is limited and as a consequence has the potential to constrain the experience of ageing (Jopp et al. 2017). Jopp et al. (2017) posits that role models have a positive function to play in how people identify with others and aid in providing motivation and acting as a positive example. Active older people as role models can motivate others to be active and counter the impact of negative stereotypes (Ory et al. 2003). Images of athletic older people have been shown to be effective in altering perceptions of ageing in younger people (Horton, Dionigi and Bellamy, 2013). It could be argued that the impact of the older women in this study, although unintentional, was a positive and welcome by-product. For the younger women the example of the older women was clearly a positive example which laid down an inspirational illustration of what can be achieved and served to inform understanding of ageing expectations. Positive images of ageing have been found to weaken the detrimental impact of negative stereotypes (Hess, Birren and Schaie, 2006). Little (2005) raises the notion that role modelling can be a viable and meaningful element of women's participation. This was clearly evident and the example of the older women served to challenge the limiting roles often associated with ageing.

\section{Future resources}

There was talk of the distant future when activities could no longer be carried out. Although one aspect of this was to talk about the anticipated regret of having to give up activities, there was also another aspect highlighting how current experiences may be used to define or influence future identity through the memories that were constructed. Memories in old age have been suggested as enabling people to cope with the uncertainty of the latter stage of life (Boutcher and Osgood 1969). In addition older people build their life stories around past events and the importance that is placed on these (Kaufman 1995). Alongside this is the notion that the memories that older adults preserve are those that aid in maintaining self-concept (Dijkstra and Kaup 2005). One woman eloquently identified this notion when she suggested that the activities and experiences would form the backdrop for when she was old and no longer able to do the activities. 
"I feel as if I'm actively writing my life story and when I am old I will take the photos out; I will be able to look back and remember all the great things I did and say life was good."

This perception of being actively engaged directing life was also observed in Kellert's (1997) work in which it was found that being in the outdoors resulted in more ownership and directing of life rather than an inert passing through. Many of the women had a strong sense that their choice to engage in outdoor adventure was actually a very positive act on their part. In addition there was a strong story telling component when they gathered at social events; where they shared anecdotes and photos of their activities, reliving events and experiences. One of the traditions that the group has is the compilation of photo books to celebrate notable birthdays, such as 50 and 60 years. These books are made up of photographs of the women engaging in the adventure activities and provide memories of adventures undertaken in previous years and are a tangible celebration of their achievements but also a strong memory aid. McAdams' (2003) work emphasises that memories and future projections can provide a means of constructing a life narrative or life story. Alongside this is the notion that people's imagined future stems from cultural life scripts and that highly positive memories aid in people' ability to maintain a life script through autobiographical memories (Rubin and Bernsten 2003). Belonging to the group and the activities undertaken have become aspects that define these women. Their notions of self have adapted and developed to incorporate group belonging and the notion of themselves as adventurers has become part of their self-identity; it has become part of their narrative about self. For the women the already strong memories of accomplishments and experiences could become a marker for a life lived well. The present experiences are in themselves an affirmative component of their current life but may also become in the future a resource for positive ageing.

Time for self

As with many women in society there is a need to balance demands and responsibilities of career, family and engaging in activity and by doing this achieve a balance that impacts positively on overall 
well-being (Whitehead and Kotze 2003). As a consequence of having to juggle multiple roles many women sacrifice opportunities to engage in activity and prioritise others leaving little time for self (Nolan 2010; Shank 1984). Participating in physical activity can be one of the areas that is jeopardised by this need to juggle roles. It is estimated that during middle age up to half of women decrease the amount of regular activity they participate in (McArthur et al. 2014), with decreases in activity of as much as 40\% (Elavsky 2009; Evenson et al. 2002). Yet physical activity participation at 50 years is more predictive of continued activity into later life than participation at earlier ages (Evenson et al. 2002). Frequently cited barriers for non-participation in middle age tend to be attributed to demands of life stage, (McArthur et al. 2014), time and exercising outdoors (Im et al. 2008) and the multiple roles and responsibilities associated with work and family (Pan et al. 2009; Carmichael, Duberley and Szmigin, 2015). Some of these women were at an age that had mixed responsibilities; some were employed full time and a couple of the younger ones still had dependent children at home. A larger number however had no children or dependent children; instead for some of the older women in the group care responsibilities had shifted to helping to look after grandchildren and the care needs of ageing parents. This meant that there was at times a tension created by organising activities around the needs of family and/or work commitments. For many women in society the normal experience is to put family and home first and themselves second (Henderson 1996; Nolan 2010). Although at times some of the group do not always participate as a consequence of family and home commitments these are infrequent. Many times the women reorganised their priorities to ensure participation and they were happy to leave other activities in their lives to another day in order to participate.

"It's more important that women just get out because the idea of staying at home every weekend and having a perfect house! I just feel - I know it's up to them but I just feel that they are missing out on so much." 
"I used to worry a lot on weekends; the house has to be tidy, I have too much washing to do the kids' rooms are a mess, but I'm less stressed about that now housework to do? It doesn't matter. Not to care as much as before; you will not get these days back."

The women adjusted their lives to manage both family and home obligations enabling them to engage in the adventure activities, which include not only a one day activity per month but sometimes weekend and week-long expeditions. This supports the findings of Boniface (2006) who found that women doing adventure activities are able to step back from other commitments and reprioritise themselves. In addition to shifting priorities it has been suggested that mid-life can be regarded as a new beginning (Utian and Boggs 1998; Finn 2000).

For many of the women in the present study joining the group and engaging in activities represented a transitional phase in their lives and that despite commitments and shifting responsibilities the women suggested that their age allowed them to look to do things for themselves. It was almost as if they were able to give themselves permission to be 'selfish' or at least able to switch the focus to themselves. The women do at times have to fit their engagement with adventure around their personal circumstances. However, adventure was seen as a priority which resulted in flexibility and creativity in managing their lives to enable engagement. Alongside this they also recognised that they were in a position of having the resources with which to do this.

".......at least I now have the time, money and space to do what I want to do. I have transport, I have good bikes."

"I think because I haven't got children because they have left home, I don't feel quite so much that I can't do things for myself, because I do have more time for myself. It's nice to meet other people and do things I enjoy." 
This would suggest that for the women doing adventure activities and being part of the group was a priority that enabled them to focus on themselves and to channel their resources into this being a significant part of their lives. Previous research has put forward that time constraints, family commitments and lack of financial independence often act as causal factors for not participating (Mutrie and Choi 2000). It would appear that this particular group of women were able to prioritise activities for themselves, stepping back at times from family commitments and work responsibilities to find time for themselves. This ability to do what they want to do has been observed in previous research and is suggestive of an ability to frame positive health behaviours and to act upon these (Smith-DiJulio et al. 2010).

\section{Conclusion}

As a consequence of diversity of experience observed in women's physical activity participation it is not possible to arrive at a simple understanding of exercise behaviour or motivation. The complexity of developing an understanding is influenced by factors such as education, time, financial resources and family commitments. The present study is limited in that it does not represent a broad spectrum of society. The women in this study are well educated and have the financial means to dedicate to adventure activities and as such it is not possible to take a broad view. However, this research does contribute to our understanding of the complex relationships between middle aged women's response to and experience of adventure.

Formation of the group was in many ways serendipitous, with a group of like-minded individuals by chance coming together to experience adventure activities. Through the auspices of a local authority adventure taster course the women experienced a diverse range of adventure activities allowing for the subsequent development of new skills and abilities. A significant aspect of this experience was the opportunity to share this with other like-minded women. From this the women joined together to form a clearly identifiable group. The women may be part of an increasing 
movement representing changing patterns of activities in middle aged women, and therefore demonstrate an ability to disprove gender and ageing stereotypes. They display a capacity to be confident in their physical abilities. Such was their enjoyment of the activities and the engagement with the group they shifted their priorities placing adventure as a significant feature of their lives. Taking up the adventure activities provided an avenue that enabled the women to develop new skills and through group membership to develop robust supportive mechanisms. In addition enjoyment of the activities facilitated a desire on the part of the women to focus on themselves, and to dedicate time for activities that gave them enjoyment and challenge.

The impact of engaging and belonging to a group of like-minded women has created a sense of the women having control and self-determined direction in their lives. As such the women's experiences of adventure activities opens up the opportunity to be different but equips them with the confidence as both individuals and as a group to feel comfortable in their identity as adventurers, as women and as ageing individuals. 


\section{References}

Akune, T. S., Muraki, H., Oka, S. H., Tanaka, H., Kawaguchi, H., Nakamura, K. and Yoshimura, N. (2014). Exercise habits during middle age are associated with lower prevalence of sarcopenia: the ROAD study. Osteoporosis International, 25, 1081-88.

Althoff, T., Sosic, R., Hicks, J.L., King, A.C., Delp, S.L. and Leskovec, J. (2017). Large-Scale Physical Activity Data Reveal Worldwide Activity Inequality. Nature 547, 336-339.

Anderson, A., Noble, K. (2001). An Analysis of Regional Variations in Sports Participation in Scotland (85). Sport Scotland, Edinburgh.

Anderson K. L. (1999). The Construction of Gender in an Emerging Sport. Journal of Sport \& Social Issues, 23, 55-79.

Arthur, S. and Nazroo, J. (2003). Designing Fieldwork Strategies and Materials. In Ritchie, J. and Lewis, J. (eds). Qualitative Research Practice: A Guide for Social Science Students and Researchers. Sage, London.

Attride-Stirling, J. (2001). Thematic Networks: an Analytic Tool for Qualitative Research. Qualitative Research, 1, 385-405.

Boniface, M. (2006). The Meaning of Adventurous Activities for 'Women in the Outdoors'. Journal of Adventure Education and Outdoor Learning, 6, 9-24.

Boucher, J. and Osgood C.E. (1969). The Pollyanna Hypothesis. Journal Verbal Learning Verbal Behaviour, 8, 1-8. 
Boyatzis, R. E. (1998). Transforming qualitative information: Thematic analysis and code development. Sage, Thousand Oaks, CA.

Boyes, M. (2013). Outdoor Adventure and Successful Ageing. Ageing and Society, 33, 644-665.

Braun, V. and Clark. V. (2006). Using thematic analysis in psychology. Qualitative Research in Psychology, 3, 77-101.

http://www.informaworld.com/smpp/content $\sim \mathrm{db}=a$ all ${ }^{\text {content }=a 795127197 \sim \text { frm=titlelink }}$

Breivik, G. (2010). Trends in Adventure Sports in a Post-Modern Society. Sport in Society 13, 260273.

Brookes, A. (2003). A Critique of Neo-Hahnian Outdoor Education Theory. Part one: Challenges to the concept of "character building." Journal of Adventure Education and Outdoor Learning, 31, 4962.

Brown, W.J., Hesch, K.C. and Miller, Y.D. (2009). Life events and changing physical activity patterns in women at different life stages. Annals Behavior Medicine, 37, 294-305.

Campbell, P.G., MacCauley, D., McCrum, E. and Evans, A. (2001). Age difference in the motivating factors for exercise. Journal Sport Exercise Psychology, 23, 191-99.

Canada, B., Stephan, Y., Caudroit, J. and Jaconelli, A. (2013). Personality and subjective age among older adults: the mediating role of age-group identification. Aging \& Mental Health, 17, 1037-43.

Carmichael, F., Duberley, J. and Szmigin, I. (2015). Older Women and their Participation in Exercise And Leisure-time Physical Activity: the Double Edged Sword of Work. Sport in Society 18, 43-60. 
Coalter, F. and Dowers, S. (2006). An Analysis of Regional Variations in Sports Participation in Scotland. (105). Sport Scotland, Edinburgh.

Creswell, J. W. (2013). Qualitative Inquiry and Research Design, Choosing Among Five Approaches. Sage, London.

Dijkstra, K. and Kaup, B. (2005). Mechanisms of autobiographical memory retrieval in younger and older adults. Memory \& Cognition, 33, 811-20.

Eccles, J.S. (1994). Understanding Women's Educational and Occupational Choices: Applying the Eccles et al. Model of Achievement Related Choices. Psychology of Women Quarterly, 18, 585-609.

Eddles-Hirsch, K. (2015). Phenomenology and Educational Research, International Journal of Advanced Research, 3, 251-60.

Edmunds, J., Duda, J. L. and Ntoumanis, N. (2010). Psychological Needs and the Prediction of Exercise-Related Cognitions and affect Among an Ethnically Diverse Cohort of Adult Women. International Journal of Sport and Exercise Psychology 8, 446-63.

Elavsky, S. 2009. Physical activity, menopause, and quality of life: the role of affect and self-worth across time. Menopause, 16, 2, 265-71.

Evenson, K.R., Wilcox. S., Pettinger, M., Brunner R., King A.C. and McTiernan A. (2002). Vigorous Leisure Activity Through Women's Adult Life: The Women's Health Initiative Observational Cohort Study. American Journal of Epidemiology, 156, 945-53. 
Ferrand, C. (2008). Motives for Regular Physical Activity in Women and Men: a Qualitative Study in French Adults with Type 2 Diabetes, Belonging to a Patient's Association. Health \& Social Care in the Community, 16, 511-20.

Finlay, L. (2008). Introducing phenomenological research. Available from:

http://www.lindafinlay.co.uk

Finn, S.C. (2000). Women in Mid-Life: a Nutritional Perspective. Journal of Women's Menopause, 9, 351-6.

Ford, N. and Brown, D. (2006). Surfing and Social Theory: Experience, Embodiment and Narrative of the Dream Glide. Routledge, London; New York.

Fredrickson, L.M. and Anderson, D.H. (1999). A Qualitative Exploration of the Wilderness Experience as a Source of Spiritual Inspiration. Journal of Environmental Psychology, 19, 21-39

Freeman, A.T., Santini, Z.I., Tyrovolas, S., Rummel-Kluge, C., Haro, J.M. and Koyanagi, A. (2016). Negative Perceptions of Ageing Predict The Onset and Persistence of Depression and Anxiety: Findings from a Prospective Analysis of the Irish Longitudinal Study of Ageing (TILDA). Journal of Affective Disorders 199, 132-38.

Hargreaves, J. (1994). Sporting Females: Critical Issues in the History and Sociology of Women's Sports. Routledge, London. 
Henderson, K. (1992). Breaking with tradition; women and outdoor pursuits. Journal of Physical Education, Recreation and Dance, 62, 49-51.

Henderson, K.A. (1996). Enhancing Women's Physical Activity Involvement. In Warren, K., (ed), Women's Voices in Experiential Education, 107-117. Kendall/Hunt, Dubuque, lowa.

Hess, T.M., Birren, J., and Schaie, K., (2006). Attitudes toward Aging and Their Effects on Behaviour. In J.E. Birren and K.W. Schaie (Eds). Handbook of the Psychology of Aging, $6^{\text {th }}$ Edition. Academic Press, San Diego, California, 379-406.

Holyfield, L, Jonas, L., and Zajicek, A. (2005). Adventure without risk is like Disneyland. In S. Lyng, (ed), Edgework: The sociology of risk-taking. Routledge, New York, 173-85.

Horton, S., Baker, J. and Deakin, J.M. (2007). Stereotypes of Aging: Their Effects on the Health of Seniors in North American Society, Educational Gerontology, 33, 1021-1035.

Horton, S., Dionigi, R.A., and Bellamy, J. (2013). Women Aged 75 and Over: Attitudes Towards Health-related Role Models and Female Masters Athletes. The International Journal of Interdisciplinary Social and Community Studies 7, 33-47.

Humberstone, B. (2000). The 'Outdoor Industry' as Social and Educational Phenomena: Gender and Outdoor Adventure/Education. Journal of Adventure Education and Outdoor Learning, 1, 21-35.

Im, E.O., Chee, W., Lim, H.J., Liu, Y., and Kim, H.K. (2008). Midlife Women's Attitudes Toward Physical Activity. Journal of Obstetric Gynecologic and Neonatal Nursing, 37, 203-213. 
James, K. (2000). "You can feel them looking at you". The experiences of adolescent girls at swimming pools. Journal of Leisure Research, 32, 262-80.

Jones, H., Millward, P. and Buraimo, B. (2011). Adult Participation in Sport, Analysis of Taking Part Survey. Department for Culture, Media and Sport, London

Jopp, D.S., Jung, S., Damarin, A.K., Mirpuri, S. and Spini, D. (2017). Who Is Your Successful Aging Role Model? Journal of Gerontology. Series B, Psychological Sciences and Social Sciences, 72, 237-47.

Kaufman, S.R. (1995). The Ageless Self, Sources and Meaning in Late Life. Wisconsin University. Wisconsin Press.

Kaplan, R. and Kaplan, S. (1989). The Experience of Nature: A Psychological Perspective. Cambridge: Cambridge Uni Press.

Kellert, S. (1997). Kinship to Mastery: Biophilia in Human Evolution and Development. Washington, DC: Island Press.

Kilgour, L. and Parker, A. (2013). Gender, Physical Activity and Fear: Women, Exercise and the Great Outdoors. Qualitative Research in Sport, Exercise and Health, 5, 43-57.

Kamijo, T. and Murakami, M. (2009). Regular Physical Exercise Improves Physical Motor Functions and Biochemical Markers in Middle-Age and Elderly Women. Journal of Physical Activity, 6, 55-62.

Kiewa, J. (2001). "Stepping around things": Gender Relationships in Climbing. Australian Journal of Outdoor Education, 5, 4-12. 
Laurendeau, J., and Sharara, N. (2008). Women could be Every Bit as Good as Guys: Reproductive and Resistant Agency in Two Action Sports. Journal of Sport and Social Issues, 32, 24-47.

Levy, B. (2009). Stereotype Embodiment: A Psychosocial Approach to Aging. Current Directions in Psychological Science 18, 332-36.

Levy, B.R., Chung, P.H., and Canavan, M. (2011). Impact of Exploratory Style and Age Type on Health across the Lifespan. In, K.L. Fingerman, C.A. Berg, J. Smith and T.C. Antonucci (eds), Handbook of Lifespan Development. Springer, New York 437-456.

Little, D.E. (2002). How do women construct adventure recreation in their lives? Journal of Adventure Education and Outdoor Learning, 2, 55-69.

Little, D.E. (2005). Role Modelling Through Physical Activity: The Generational Gift of Women. Eleventh Canadian Congress on Leisure Research. Malaspina University College, Nanaimo, B.C. Canada. Canadian Association for Leisure Studies.

Loeffler, T.A. (1997). Assisting women in developing a sense of competence in outdoor programs. The Journal of Experiential Education. 20, 119-23.

McAdams, D.P. (2003). Identity and the Life Story. Lawrence Erlbaum Associates Publishers, Mahwah NJ 
McArthur, D., Dumas, A., Woodend, K., Beach, S. and Stacey, D. (2014). Factors influencing adherence to regular exercise in middle-aged women: a qualitative study to inform clinical practice. BMC Women's Health 14, 49.

McCrae, R.R. (1987). Creativity, divergent thinking, and openness to experience. Journal of Personality and Social Psychology, 52, 1258-65.

Meisnar, B.A. (2012). A Meta-Analysis of Positive and Negative Age Stereotype Priming Effects on Behaviour Among Older Adults. Journals of Gerontology Series B: Psychological Sciences and Social Sciences, 67, 13-17.

Mutrie, N. \& Choi, P.Y.L. (2000), 'Is 'fit' a feminist issue? Dilemmas for exercise psychology' Feminism and Psychology, 10, 4.

Noble, H. and Smith, J. (2015). Issues of Validity and Reliability in Qualitative Research. Evidence Based Nursing, 18, 34-5.

Nolan, T and Priest, S. (1993). Outdoor Programmes for Women Only? Journal of Adventure Education and Outdoor Leadership, 10, 14-17.

Nolan V.T. (2010). Participation in Physical activity: An empirical study of working women's perceptions. African Journal for Physical, Health Education, Recreation and Dance (AJPHERD), 16, $355-72$. 
Ory, M., Hoffman, M.K., Hawkins, M., Sanner, B. and Mockenhaupt, R. (2003). Challenging Aging Stereotypes: Strategies for Creating a More Active Society. American Journal of Preventative Medicine, 25, suppl 2, 164-171.

Pan, S.Y., Cameron, C., Desmeules, M., Morrison, H., Craig, C.L., and Jiang, X. (2009). Individual, social, environmental, and physical environmental correlates with physical activity among Canadians: a cross-sectional study. BMC Public Health, 9, 21.

Pfister, G. (2012). It Is Never Too Late to Win - Sporting Activities and Performance of Ageing Women, Sport in Society, 15, 369-84.

Pohl, S.L., Borrie, W.T. and Patterson, M.E. (2000). Women, Wilderness, and Everyday Life: A documentation of the connection between wilderness recreation and women's everyday lives. Journal of Leisure Research, 32, 415-34.

Riessman, C. K. (1993). Narrative Analysis. Sage, Newbury Park, CA.

Roth, A. and Basow, S.A. (2004). Femininity, Sports and Feminism: Developing a Theory of Physical Liberation. Journal of Sport and Social Issues, 28, 245-65.

Rubin, D.C. and Bernsten, D. (2003). Life Scripts help maintain autobiographical memories of highly positive, but not highly negative events. Memory \& Cognition, 31, 1-14.

Scottish Government. (2015). The Scottish Health Survey 2014 edition. A National Statistics Publication for Scotland. www.gov.scot/scottishhealthsurvey 
Scottish Government. (2016). Scotland's People Annual Report: Results from the 2015 Scottish Household Survey. http://www.gov.scot/Resource/0050/00506173.pdf

Scraton, S. and Watson, B. (1998). Gendered cities: Women and public leisure space in the "postmodern city". Leisure Studies, 17, 123-37.

Shank, J.W. (1984). An exploration of leisure in the lives of dual career women. Journal of Leisure Research, 18, 300-19.

Smith-DiJulio, K., Windsor, C. and Anderson, D. (2010). The Shaping of Midlife Women's Views of Health and Health Behaviors. Qualitative Health Research, 20, 966-76.

Sport England. (2017). Active Lives Adult Survey, May16/17 Report. Sports England, London. https://www.sportengland.org/media/12458/active-lives-adult-may-16-17-report.pdf

Thomas, D.R. (2017). Feedback from Research Participants: Are Member Check Useful in Qualitative Research? Qualitative Research in Psychology, 14, 23-41.

Thorpe, H. (2011) Snowboarding Bodies in Theory and Practice. New York: Palgrave Macmillan.

Tuckett, A. G. (2005). Applying thematic analysis theory to practice: A researcher's experience. Contemporary Nurse, 19, 75-87.

Utian, W.H. and Boggs. P.P. (1998). The North American Menopause Society Survey. Part 1 PostMenopausal Women's Perceptions about Menopause and Midlife. Menopause, 6, 122-8. 
Von Eckartsberg, R. (1998). Existential-Phenomenological Research In. R. Valle (Ed),

Phenomenological Inquiry in Psychology, Existential and Transpersonal Dimensions. Springer, US, 21-

61

Whitehead, T. and Kotze, M.E. (2003). Career and life-balance of professional women: A South African study. South African Journal of Human Resource Management, 1, 77-84.

Wolff, J.K., Schuz, B., Ziegelmann, J.P., Warner, L.M. and Wurm, S. (2015). Short-term Buffers, but Long-term Suffers? Differential Effects of Negative Self-perceptions of Aging Following Serious Health Events. Journal of Gerontology B-Psychol Science and Social Science 00 1-7.

Wurm, S., Warner, L.M., Ziegelmann, J.P., Wolff, J.K. and Schuz, B. (2013). How Do Negative SelfPerceptions of Aging become a Self-Fulfilling Prophecy? Psychology and Aging, 28, 1088-97.

Accepted $4^{\text {th }}$ September 2018 
Table 1

Participant information

\begin{tabular}{|c|c|l|c|l|l|}
\hline Participant & Age & Marital Status & Children & Employment Status & Education \\
\hline 1 & 42 & Married & 2 & Part time & Post Graduate \\
\hline 2 & 48 & Married & 3 & Full time & $\begin{array}{l}\text { Professional } \\
\text { qualification }\end{array}$ \\
\hline 3 & 53 & Married & 2 & Full time & $\begin{array}{l}\text { Professional } \\
\text { qualification }\end{array}$ \\
\hline 4 & 58 & Married & 2 & Retired & Post Graduate \\
\hline 5 & 59 & Married & 2 & Full time & $\begin{array}{l}\text { Professional } \\
\text { qualification }\end{array}$ \\
\hline 6 & 36 & Single & 0 & Full time & Degree \\
\hline 7 & 44 & Married & 2 & Part time & Degree \\
\hline 8 & 53 & Single & 1 & Full time & Post graduate \\
\hline 9 & 44 & Single & 0 & Full time & $\begin{array}{l}\text { School } \\
\text { completion }\end{array}$ \\
\hline 10 & 58 & Married & 3 & Semi-retired & Post graduate \\
\hline 11 & 61 & Widow & 3 & Retired & $\begin{array}{l}\text { Professional } \\
\text { qualification }\end{array}$ \\
\hline 12 & 64 & Married & 3 & Retired & $\begin{array}{l}\text { Professional } \\
\text { qualification }\end{array}$ \\
\hline 13 & 47 & Single & 0 & Full time & Degree \\
\hline 14 & 53 & Single & 0 & Full time & Post graduate \\
\hline
\end{tabular}

Table 2

\begin{tabular}{|c|c|}
\hline MAIN & SUBORDINATE \\
\hline \multirow[b]{2}{*}{ Group belonging } & Social Support \\
\hline & Being different from social norms \\
\hline \multicolumn{2}{|l|}{ Self-perception and Identity } \\
\hline \multirow{4}{*}{ Ageing } & Decline and regret \\
\hline & Role Models \\
\hline & Future Resources \\
\hline & Time for Self \\
\hline
\end{tabular}

